\title{
Endonucleolytic cleavage of a maternal homeo box mRNA in Xenopus oocytes
}

\author{
Bob D. Brown and Richard M. Harland \\ Division of Biochemistry and Molecular Biology, University of California, Berkeley, California 94720 USA
}

\begin{abstract}
We have identified a messenger RNA (mRNA) sequence from a Xenopus homeo box-containing gene that is the target for a sequence-specific endoribonuclease in vivo. Synthetic RNA transcribed from an allele of the maternal gene Xlhbox $2 B$ is efficiently cleaved when injected into Xenopus oocytes. The cleavage sequence lies between the protein-coding region and a 600-base 3 '-untranslated region. Intermediates in degradation are readily observed: Both the $5^{\prime}$ and $3^{\prime}$ products of cleavage are recovered, thus showing that the cleavage activity is an endonuclease. When a 90-base region of the Xlhbox $2 B$ sequence is inserted into a second homeo box RNA that is normally stable, it is sufficient to confer an identical cleavage reaction on the hybrid RNA. The cleaved region contains a repeated sequence motif and is cut at multiple sites. Inhibition of translation does not affect the rate or extent of cleavage, while the coinjection of antisense RNA complementary to the 90-base region completely blocks the reaction. Because most mRNAs are not found on polysomes during oogenesis, translation-independent cleavage at such sites may provide a novel post-transcriptional mechanism to regulate the amount of mRNA available for embryogenesis.
\end{abstract}

[Key Words: Xenopus; RNA stability; endoribonuclease; homeo box]

Received May 22, 1990; revised version accepted August 22, 1990.

The stability of messenger RNA (mRNA) plays a crucial role in the regulation of gene expression, but as yet the determinants of differential mRNA stability in eukaryotic cells have not been characterized in biochemical detail (for review, see Brawerman 1987, 1989; Shapiro et al. 1987; Cleveland and Yen 1989). Attempts to identify the initial events in RNA turnover have been hampered by the problem that intermediates in degradation are usually difficult to detect because cells contain exonucleases that rapidly degrade RNA after initial destabilizing events (Ross 1988).

Protection of intact mRNA against general exonucleases is afforded by specialized structures at both the $5^{\prime}$ and $3^{\prime}$ ends of the molecules. A $5^{\prime}$ cap on most mRNAs, with the exception of some viruses (for review, see Banerjee 1980), is crucial for mRNA stability because it blocks the activity of $5^{\prime}$ to $3^{\prime}$ exonucleases on both natural and synthetic RNAs (Furuichi et al. 1977; Green et al. 1983). Poly(A) tails, found at the $3^{\prime}$ end of most eukaryotic mRNAs, have been shown to be resistant to $3^{\prime}$ to $5^{\prime}$ nucleases when bound by poly(A)-binding proteins (Bergmann and Brawerman 1977; Bernstein et al. 1989). Further evidence that the ends of RNA are the main target for cellular nucleases comes from injections of circular RNAs into Xenopus embryos. Such RNAs, lacking either $5^{\prime}$ or $3^{\prime}$ ends, are found to be exceptionally stable when compared with linear RNA molecules (Harland and Misher 1988).

It is not surprising, then, that removal of the poly(A) tail appears to be a crucial event in the degradation of many mRNAs. During selective turnover of c-myc and c-fos mRNAs, deadenylation occurs prior to the rapid degradation of the remainder of the molecules (Brewer and Ross 1988; Wilson and Treisman 1988). Deadenylation prior to degradation has also been reported in Xenopus oocytes and embryos (Colot and Rosbash 1982; Hyman and Wormington 1988). Although the specific effect of the poly(A) tail on stability and translation in many systems remains controversial (for review, see Sachs and Davis 1989; Jackson and Standart 1990), it is clear that enzymatic addition of a poly $(\mathrm{A})$ tail to mRNA synthesized in vitro stabilizes it after injection into both oocytes and developing embryos (Drummond et al. 1985; Harland and Misher 1988).

The relative influences of endonucleases and exonucleases and their interactions with the translation apparatus of the cell to destabilize mRNAs differentially are not well understood. Destabilization of mRNA in vivo is usually associated with either translation of the target mRNA or translation of total cellular mRNA (for review, see Ross 1988; Brawerman 1989). For example, tubulin mRNA degradation caused by an increase in free tubulin subunits is based on the recognition of the nascent amino termini on polysomes, and not strictly on the tubulin mRNA sequence (Yen et al. 1988), thus accounting for the fact that only polysomal mRNA is subject to degradation (Pachter et al. 1987). During histone mRNA degradation ribosomes must translate to the vicinity of the destabilizing sequence for rapid degradation to occur (Graves et al. 1987). In addition, translational 
inhibitors generally stabilize mRNAs (for review, see Shaw and Kamen 1986; Ross 1988; Brawerman 1989). One mechanism to account for this is that the nucleases that initiate degradation are associated with the ribosome and translation inhibition prevents access of the nucleases to the mRNA. However, an alternative hypothesis is that the nuclease activity is itself unstable and must continually be replenished by translation; this is suggested by experiments in which the selective destabilizing activity in a cell-free extract was measured and found to be depleted in extracts from cycloheximide-treated cells (Brewer and Ross 1989).

Xenopus oocytes offer a simple system in which to study RNA stability because most mRNAs that have been examined in these oocytes are unusually stable, and the absolute levels of most endogenous mRNA species are established very early in oogenesis (Golden et al. 1980; Dworkin and Dworkin-Rastl 1985). Many RNAs persist throughout oogenesis (Ford et al. 1977; for exceptions, see Dworkin and Dworkin-Rastl 1985; Dworkin et al. 1985). Furthermore, synthetic RNAs without poly(A) tails persist for many hours after injection (Drummond et al. 1985; Harland and Weintraub 1985; Galili et al. 1988; Kruys et al. 1989). For these reasons, and because of the low level of RNases in oocytes (or the presence of nuclease inhibitors; Xing and Worcel 1989), intermediates in the degradation of specifically destabilized mRNAs may be detectable. The identification of such intermediates should allow the detailed characterization of the initial cleavage events in mRNA turnover.

In this work we have examined the turnover of synthetic Xlhbox2 mRNA. Xlhbox2 is a homeo box gene of the Antennapedia class whose transcripts are found in Xenopus oocytes, eggs, and embryos (Müller et al. 1984; Wright et al. 1987; A. Hemmati-Brivanlou and B.G. Condie, unpubl.). Absolute Xlhbox2 mRNA levels in Xenopus oocytes are quite high in previtellogenic oocytes, but decrease to a low level in later stages (Wright et al. 1987), thus posing the question of how Xlhbox2 mRNA is specifically destabilized in a population of RNAs that are normally extremely stable. In addition, two XIhbox2 genes have been found in the Xenopus genome; these are referred to as type A (formerly MM3) and type B (formerly p52) (Müller et al. 1984; Wright et al. 1987; Fritz et al. 1989). Small sequence differences in the coding regions of the type $A$ and type $B$ genes result in 11 substitutions and two deleted residues out of 220 amino acids, but the largest sequence difference is a 123-base deletion in the $3^{\prime}$-untranslated region ( 3 ' UTR) of Xlhbox2A (Fritz et al. 1989). As we show below, this sequence that is deleted from Xlhbox $2 A$ may be critical in regulating the stability of Xlhbox2B mRNA.

To investigate the mechanism of turnover, we injected synthetic Xlhbox $2 B$ mRNA into oocytes and show that sequence-specific endonucleolytic cleavages are detectable within $30 \mathrm{~min}$ after injection. Both the $5^{\prime}$ and $3^{\prime}$ products of cleavage are recovered and directly observed. Cutting occurs when the translation of the $X 1 h b o x 2 B$ RNA is blocked by injecting it as an uncapped molecule or when total cellular translation is inhibited. We have also identified the sequence responsible for conferring cleavage on Xlhbox $2 B$ by transferring it into a normally uncleaved, synthetic mRNA that encodes Xhox36 (Condie and Harland 1987). We are able to recover both $5^{\prime}$ and $3^{\prime}$ products of cleavage; therefore, this is an unambiguous description of endonucleolytic cleavage of a cellular mRNA in vivo.

\section{Results}

\section{Xhox45 RNA injected into oocytes is cleaved}

To study the degradation of Xlhbox2 RNA, we made use of cDNA clones isolated in a screen for Antennapedia class homeo boxes (Condie and Harland 1987). The cDNA clone Xhox 45 is related to Xlhbox2B. Synthetic RNAs, diagramed in Figure 1A, were transcribed in vitro in the presence of $\left[\alpha^{-32} \mathrm{P}\right] \mathrm{CTP}$ and then injected into the cytoplasm of Xenopus oocytes. After incubation and reisolation the RNAs were analyzed by denaturing gel electrophoresis and autoradiography, as seen in Figure 1B.

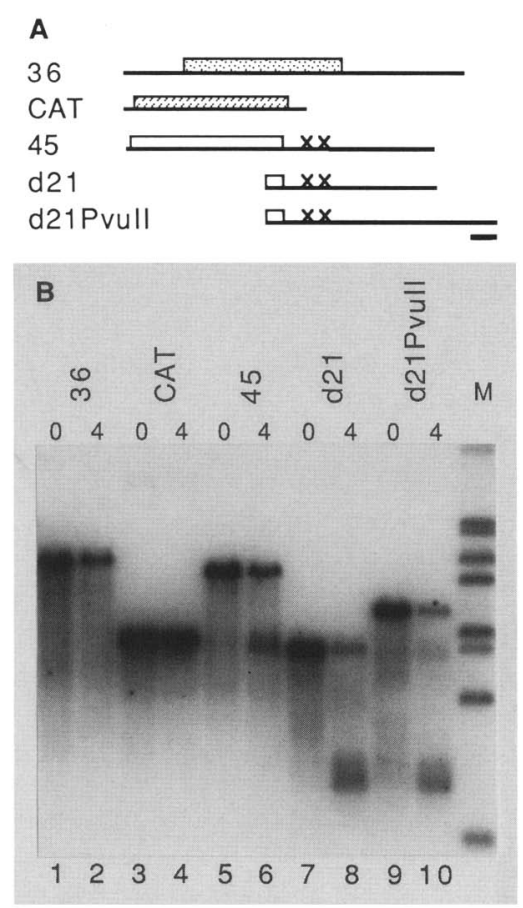

Figure 1. Injection of RNA into Xenopus oocytes and detection of mRNA cleavage. (A) Structures of the RNAs used in injection experiments. Boxed regions indicate protein-coding sequences. The bar below the constructs is 100 bases in length. (B) Autoradiograph of mRNAs injected into Xenopus oocytes, reisolated with total cellular RNA, and run on a denaturing agarose gel at one oocyte per lane. The time of reisolation after injection is given in hours above each lane. Denatured $\lambda$ Hin$\mathrm{dIII} / E c o \mathrm{RI}$ markers from $2 \mathrm{~kb}$ to $0.125 \mathrm{~kb}$ are shown. Lanes 2 and 4 do not show any discrete degradation products from Xhox36 or CAT RNAs. Lanes 6,8 , and 10 show the appearance, after $4 \mathrm{hr}$, of RNA species shorter than originally injected. $(x)$ The approximate positions of the $3^{\prime}$ ends of these shortened RNAs are shown in $A$. 
As controls, we injected two RNAs: Chloramphenicol actyltransferase (CAT), which has been shown previously to be stable in oocytes (Harland and Weintraub 1985) and Xhox36. The amount of full-length Xhox36 transcripts decreases, but no distinct degradation products are detected (Fig. 1B, lane 2). Similarly, no distinct degradation products are observed for the CAT RNA (Fig. 1B, lane 4). In contrast, the amount of fulllength Xhox45 transcript, 1342 bases in length, is seen to decrease after $4 \mathrm{hr}$ and a cleavage product of $\sim 800$ bases in length appears below it (Fig. 1B, lane 6). To characterize the cleavage reaction further, we injected truncated derivatives of Xhox 45 RNA. The $\mathrm{d} 21$ construct is a large $5^{\prime}$ deletion of Xhox 45 in which only 53 bases of the coding sequence and the 650-base 3 '-untranslated region remain (see Fig. 1A), producing a transcript with a length of 752 bases. This RNA is cleaved to yield a product of $\sim 200$ bases, although somewhat longer material can be seen in a smear above the most intense band (Fig. 1B, lane 8 ). To test the effect of altering $3^{\prime}$ sequences we extended the $\mathrm{d} 21$ transcript by linearizing the $\mathrm{d} 21$ plasmid with $P v u I I$. This modified template produces a d21 transcript lengthened at its $3^{\prime}$ end by 270 bases of vector sequence, for a total length of 1022 bases. This transcript is also cleaved to yield a product that is identical in length to that from d21 (Fig. 1B, lane 10).

The length of the degradation product bands observed for the Xhox45 RNAs shown in Figure 1B is dependent only on the length of RNA on the 5' side of the cleavage site (cf. Fig. 1B, lanes 6, 8, and 10); furthermore, the observed size decrease of each injected RNA species corresponds precisely to the length of RNA on the 3' side of the putative cleavage site. These results, and the results of injections using other $5^{\prime}$ and $3^{\prime}$ deletion and insertion constructs (Fig. 2B, and data not shown), demonstrate that the shortened bands observed in Figure 1B are the capped 5' ends of the RNA molecules. The unlikely possibility that the shortening is due to splicing is also eliminated, because a splicing event would remove a constant length of sequence from each RNA.

Because changes to the $5^{\prime}$ and $3^{\prime}$ ends of Xhox 45 RNAs do not alter the efficiency of cleavage, the recognition of the Xhox 45 message does not require sequences at the termini of the RNA. We also find that the addition of $\sim 200$-base poly(A) tails to the $3^{\prime}$ end of the RNA using poly(A) polymerase has no effect on the cleavage reaction (data not shown).

\section{Confirmation that the Xhox 45 cleavage activity is an endonuclease}

Sequence-dependent targeting of a $3^{\prime}$ to $5^{\prime}$ exonuclease to the Xhox 45 mRNA could produce shortened $5^{\prime}$ fragments if the exonuclease were to stall in a few specific regions or if it were to release the RNA after degrading the targeting sequence itself. Therefore, an unequivocal demonstration of an endonuclease activity requires the observation of both the $5^{\prime}$ and $3^{\prime}$ RNA fragments, as shown in Figure 2.

An autoradiograph of radiolabeled d21 RNA at high resolution is shown in Figure 2a. The bands marked B (Fig. 2a, lanes 2-6) correspond with the capped 5' fragments of $\mathrm{d} 21$ seen at lower resolution in Figure 1B. In this short time course, analyzed by polyacrylamide gel electrophoresis, these $5^{\prime}$ fragments are resolved into four major bands (Fig. 2a, arrowheads), revealing that cleavage occurs at several sites. Most importantly, however, bands corresponding in size to putative $3^{\prime}$ cleavage fragments (A in Fig. 2a, lanes 2-4) are also detected. Because of the structure of the d21 RNA, the 3' fragments are longer than the capped $5^{\prime}$ fragments (Fig. 1A).

The size spread of the two sets of bands is consistent with endonucleolytic cleavage of d21 RNA: Their approximate respective lengths add up to the total 752 base length of $d 21$. Note that the uncapped 3' fragments decay more quickly than the shorter capped $5^{\prime}$ ends, explaining why these bands were not detected in the longer time course shown in Figure 1. CAT mRNA was used as the control, and although the level of this RNA decreases after $8 \mathrm{hr}$ and despite the long exposure, no distinct degradation products are detected (Fig. 2a, lane 8).

To confirm the identity of the bands shown in Figure 2a, unlabeled RNAs were injected and the cleavage products were visualized with $5^{\prime}$ - and 3 '-specific probes in a Northern blot experiment shown in Figure 2b. In lanes 1-4, d21 and d133 RNAs (diagramed in Fig. 2d) were probed with the $3^{\prime}$-most 280 bases of $d 21$. Specific bands below the full-length injected RNA were detected in the 80-min samples (A in Fig. 2b, lanes 2 and 4). These cleavage products, detected by the 3 ' probe, are identical in size even though full-length $\mathrm{d} 21$ and $\mathrm{d} 133$ RNAs differ in length by 81 bases at their $5^{\prime}$ ends, thus confirming their identity as $3^{\prime}$ cleavage fragments.

A probe complementary to the $5^{\prime} 201$ bases of $d 21$ was used to reprobe the blot, and the results are shown in Figure 2b, lanes 5-8. As expected, small and diffuse RNAs corresponding to the $5^{\prime}$ cleavage products were detected $\left(B_{\mathrm{d} 21}\right.$ in lane 6 and $B_{\mathrm{d} 133}$ in lane 8), and they differ in size according to the size difference of the injected full-length RNAs (cf. with Fig. 1, lanes 8 and 10). The $5^{\prime}$ probe does not detect the $3^{\prime}$ species labeled A (Fig. 2b, lanes 2 and 4).

As a final confirmation of the identity of the bands shown in Figure 2, a and b, 5' - and 3'-specific DNA oligonucleotides were used with RNase $\mathrm{H}$ to separately destroy the d21 RNA cleavage fragment sets, as shown in Figure 2c. Three samples of cold d21 RNA reisolated 80 min after injection were treated with RNase $\mathrm{H}$, plus or minus specific DNA oligonucleotides /diagramed in Fig. $2 \mathrm{~d}$ ), and analyzed by Northern blotting. The blot was probed with full-length $\mathrm{d} 21$. The control shows that RNase $\mathrm{H}$ treatment without DNA oligonucleotides leads to some general RNA degradation, but the cleavage products are still visible (Fig. 2c, lane 9). The $3^{\prime}$ fragments are again labeled $\mathrm{A}$, and the $5^{\prime}$ fragments are labeled B.

An identical RNA sample, after treatment with RNase $\mathrm{H}$ and the $3^{\prime}$-specific oligonucleotide, is shown in lane 10 (Fig. 2c). The $3^{\prime}$ fragments are destroyed, but the $5^{\prime}$ 

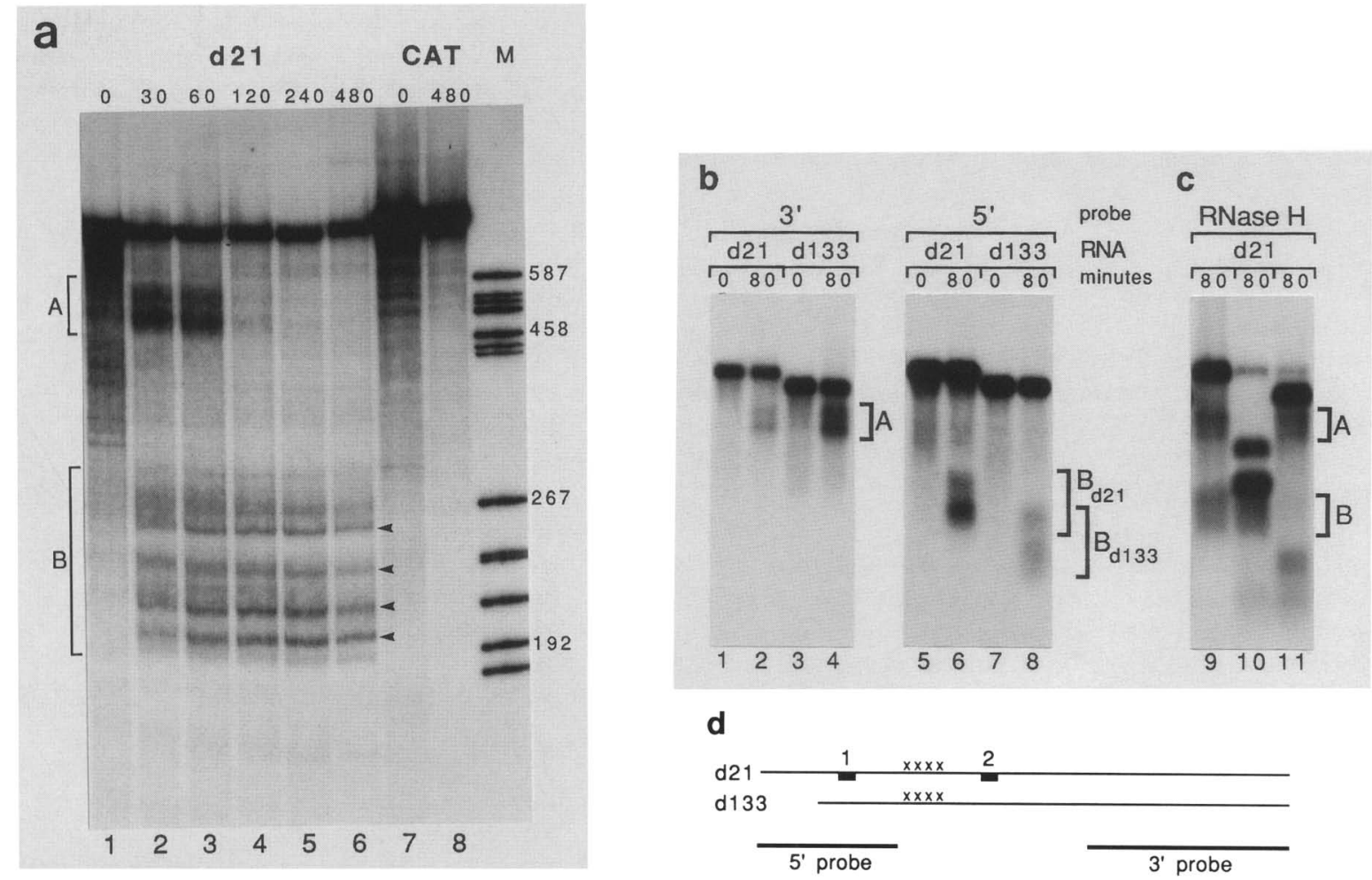

Figure 2. Detection of both the $5^{\prime}$ and $3^{\prime}$ cleavage products. (a) Capped RNA from the $\mathrm{d} 21$ construct (Fig. 1A) was injected and reisolated after the times indicated in minutes above the lanes. The gel was $4 \%$ acrylamide $/ 8 \mathrm{M}$ urea, with total RNA from one oocyte per lane. Bracket A marks the uncapped 3' cleavage fragments; bracket B marks the separately resolved 5'-capped fragments. Arrowheads mark the most intense $5^{\prime}$ cleavage product bands (lanes $3-6$ ). Note the rapid disappearance of the uncapped $3^{\prime}$ fragments relative to the $5^{\prime}$ fragments (lanes 3 and 4 ). In spite of the overexposure of the CAT samples (lanes 7 and 8 ), no distinct degradation products of CAT mRNA are seen. Because of the exposure, a small fraction of full-length d21 appears to resist cleavage (cf. lane 1 with lane 6), but completion of the reaction is seen in longer time courses. The DNA markers are denatured pBR322 HaeIII fragments sized 587, 540, $504,458,434,267,234,213,192$, and 184 bases from top to bottom. Full-length d21 RNA is 752 bases in length. (b) Northern blot analysis of $\mathrm{d} 21$ and d133 RNA cleavage; 81 bases were deleted from the 5 ' end of the $\mathrm{d} 21$ construct to produce d 133 . Times in minutes are given above each lane. Lanes 1-4 were probed with a $3^{\prime}$-specific probe and in the 80 -min time points (lanes 2 and 4 ), distinct cleavage product bands of equal length can be seen (A). Lanes 5-8 are 1-4 reprobed with a 5' -specific probe, and 5' cleavage products of unequal lengths are detected (lane $6, \mathrm{~B}_{\mathrm{d} 21} ;$ lane $8, \mathrm{~B}_{\mathrm{d} 133}$ ). The size difference of the $5^{\prime}$ cleavage products corresponds to the size difference of $\mathrm{d} 21$ and d133 RNAs at their $5^{\prime}$ ends. (c) A Northern blot probed with full-length d21 showing specific oligodeoxynucleotide/RNase $\mathrm{H}$ identification of the cleavage fragments in 80-min time point d21 RNA. A sample of the same d21 RNA used in $b$ (lanes 2 and 6) shows some increased background due to general degradation when treated with $\mathrm{RNase} \mathrm{H}$ alone, but the cleavage products are both visible and indicated as $A$ and $B$ for $3^{\prime}$ and 5' fragments, respectively (lane 9). Treatment with RNase $H$ and a $3^{\prime}$-specific complementary DNA oligonucleotide destroys only the full-length RNA and the $3^{\prime}$ cleavage bands (bracket A, cf. lane 10 with lane 9 ), while an identical treatment using a $5^{\prime}$-specific oligonucleotide destroys only the full-length RNA and the 5' cleavage bands (bracket B, cf. lane 11 with lane 9). (d) A diagram of the constructs used in $a-c$. d133 RNA is identical to d21 except for an 81-base deletion near its $5^{\prime}$ end. The positions of the $5^{\prime}$ - and $3^{\prime}$-specific Northern blot probes are shown as heavy bars. The positions of the $5^{\prime}$-specific $(1)$ and $3^{\prime}$-specific (2) DNA oligonucleotides used for the RNase $\mathrm{H}$ assay are shown as solid black boxes. $(\times)$ The cleavage region.

fragments remain unchanged (cf. lane 9 with lane 10). The result of the complementary experiment using a $5^{\prime}$ end-specific DNA oligonucleotide is shown in lane 11 (Fig. 2c). The $5^{\prime}$-specific oligonucleotide and RNase $\mathrm{H}$ destroy the $5^{\prime}$ fragments but not the $3^{\prime}$ fragments (cf. lane 9 with lane 11). New bands that appear in lane 10 (heavy pair of bands between A and B) and lane 11 (heavy bands above $\mathrm{A}$ and below $\mathrm{B}$ ) result from oligonucleotide/ RNase $\mathrm{H}$ treatment of the full-length injected d21 RNA, with small contributions from the $3^{\prime}$ or $5^{\prime}$ cleavage products (see Fig. 2d).

The results presented in Figure 2 confirm that Xhox 45 cleavage is endonucleolytic. Both $5^{\prime}$ and $3^{\prime}$ RNA frag- ments of transcripts derived from Xhox 45 are clearly detectable and identifiable.

\section{Localization of the endonuclease recognition sites}

In an attempt to localize the end points of the cleavage fragments more closely, we carried out S1 nuclease protection analysis on the total RNA isolated from injected oocytes. Figure $3 a$ shows the results by use of a $5^{\prime}$ fragment-specific probe. Lanes $\mathrm{g}-\mathrm{k}$ show an accumulation of $5^{\prime}$ cleavage products (arrowheads) corresponding to those seen in Figure 2. The probe length and position relative to the new $3^{\prime}$ ends of these fragments allow only 


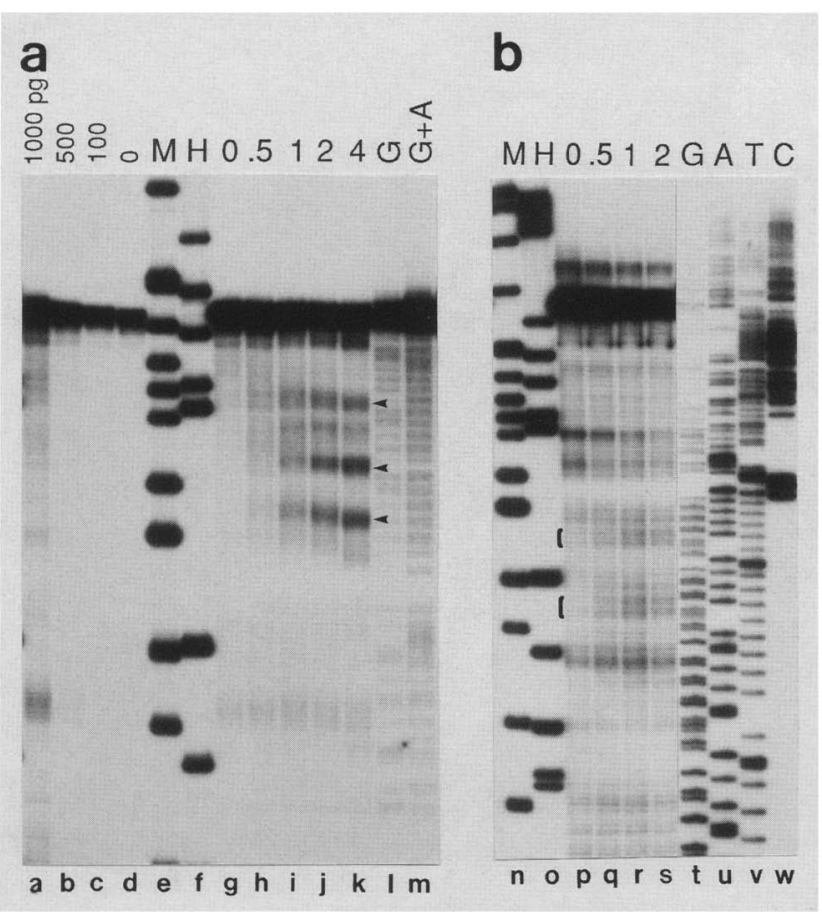

Figure 3. Localization of the $5^{\prime}$ and $3^{\prime}$ cleavage product ends by $\mathrm{S} 1$ nuclease protection. $\mathrm{M}$ and $\mathrm{H}$ indicate $\mathrm{pBR} 322 \mathrm{MspI}$ and HaeIII markers, respectively. (a) A probe specific to the $5^{\prime}$ fragments was used to analyze RNA from injected oocytes. RNA was isolated after the times of incubation shown in hours above lanes $g-k$. Strong protection bands (arrowheads) result from 5' cleavage fragments that accumulated during the course of the injection experiment (lane $k$ ). These bands correspond to the three shortest 5 ' cleavage product bands, whereas the band of increasing intensity just below the full-length probe corresponds to the fourth and longest 5 ' cleavage product (Fig. 2a, arrowheads). Lanes $a-d$ are controls of uninjected d21 RNA added to the $S 1$ reaction in the amounts given above the lanes. $\mathrm{G}$ and $\mathrm{G}+\mathrm{A}$, (lanes 1 and $\mathrm{m}$ ) are sequencing ladders of the $5^{\prime}$ probe. $(b)$ A probe specific to the $3^{\prime}$ fragments was used to analyze oocyte RNA from the same injection experiment shown in $a$. The brackets mark groups of bands resulting from the uncapped 3 ' fragments of d21 RNA. These correspond to the positions of the two smallest $5^{\prime}$ fragment bands (Fig. 2a, arrowheads). Lanes $t-w$ are dideoxy sequencing ladders of the $3^{\prime}$ probe.

three of the four bands indicated by arrows in Figure 2 to be seen clearly, although the fourth and longest is visible just below the full-length probe band (lane k). S1 nuclease protection, using a probe specific for $3^{\prime}$ cleavage products, is shown in Figure $3 \mathrm{~b}$. As expected, due to much faster degradation of these uncapped fragments, the protected probe fragments appear as groups of faint bands. Two sets of fragments complementary in size to the two smallest $5^{\prime}$ cleavage products are indicated by brackets. The probe positions relative to $\mathrm{d} 21$ are shown in Figure 4b.

On the basis of the sizes of the arrowed $5^{\prime}$ cleavage fragments in Figure 2, and the $5^{\prime}$ protection bands in Figure 3a, the approximate areas of the d21 sequence into which the four distinct cleavage product bands map are shown in Figure 4a (horizontal brackets above the sequence). Most of the region is a repeat of a 4-base unit, ACCT, but with slight variations that may break the sequence into larger functional repeat units /see Discussion).

\section{The Xhox45-cleaved sequence is necessary for recognition and is also sufficient to confer endonucleolytic cleavage on another $m R N A$ species}

We determined whether the region into which the endonuclease sites map is necessary and sufficient for the cleavage of Xhox 45 mRNA by using the constructs diagramed in Figure 5. An autoradiograph from a typical set of injection experiments with these RNAs is shown in Figure 6.

Two SpeI restriction sites were utilized to internally delete 336 bases from Xhox 45 to produce the clone $45 \Delta$ SpeI. This deletion completely removes the cleavage sites and results in an RNA $\sim 1 \mathrm{~kb}$ in length with a 314base $3^{\prime}$-untranslated region. As can be seen in Figure 6A, $45 \Delta$ SpeI is at least twice as stable as intact Xhox 45 (see also Fig. 5) and shows no sign of the endonucleolytic cleavage. This region is therefore required for Xhox 45 cleavage.

Shaw and Kamen (1986) have demonstrated an instability sequence of fused ATTTA repeats in GM-CSF (granulocyte macrophage colony-stimulating factor) mRNA. Because a general motif of fused ACCTA repeats in the Xhox 45 cleavage region is faintly reminiscent of this sequence, RNA transcribed from a human GM-CSF clone was tested as an additional control (Fig. 6A). GM-CSF is extremely stable in oocytes, confirming

a

608 CCTCTAACAG CCAAGAAAAG CCGGAGACTG AGGAGGAGGA GGAGGAGGAG GAATGAAGTG GCCCCAATGG 678 ACTAGTGAGC ACGAGATGAT CCACTGACCC ATACTACCTA CATCCCTTTT CTACTAGAGG GTTAGCTACC 748 TACCTACCTA CCCACCTAAC TACCTACCTA CCCACCTACT TACCTACCTA CCTTCCCACC TAACTACCTA 818 CTIACCTAAC TACCTACCTA CTCACCCACC GACCTACCCA CCTGTCCCCT CTGTACAACC ACTITCTATG 889 TGGCATCTCA TTTACCCAAT TATTCAACAA GCGTCGCAGC ATTTPCATTT TTTCTACCTT TTTTTTTTTT 958 TTTTGAAGAA TCCTAGTCCC TGAGAGATCG TGGTCTTTAA AAAAAAAATT CCTTGTGACT GTGTTTGACT 1098 ACTCAGTCCA GTAATTGGG AAATCTCCTT TCCTCCTCTT CCCTATTGAC AGATATATGT GTGTAATATT 1168 TTTTGTGCCA TTTGAAAAAT GTGATGTACA ATTTAATTTT AATATAATTT AATCATAGAC TCCTGTGCTT 1308 ATTC

b

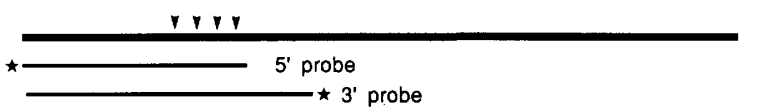

Figure 4. Sequence of the d21 clone derived from Xhox 45. $|a|$ The sequence of the Xhox 45 deletion subcloned to produce BS- $^{-}$21, (see Materials and methods). Base numbering is according to Wright et al. (1987). The 90-base region subcloned into $X$ hox 36 to produce $36 \times 1$ is underlined. The cleavage site ranges, as mapped by the arrowed fragments in Fig. 2a and by the 5 ' fragment $\mathrm{S} 1$ analysis in Fig. 3a, are indicated by the horizontal brackets above the sequence. $(b)$ Diagram of the $\mathrm{d} 21$ RNA and the S1 probes used in Fig. 3. The heavy bar represents d21 RNA, the lighter bars represent the probes, and the stars indicate the position of the label in each probe. The vertical arrowheads indicate the relative positions of the cleaved areas of $\mathrm{d} 21$ shown in $a$. 


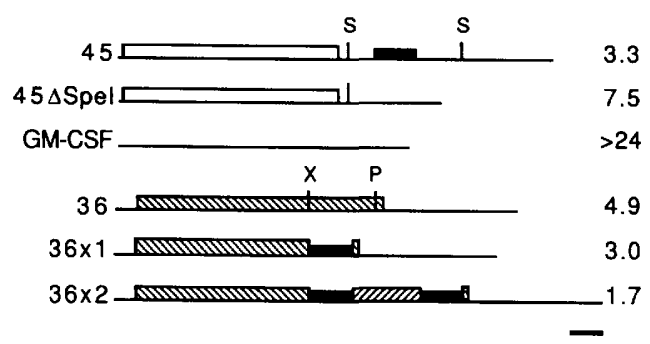

Figure 5. Structure and half-lives of the RNAs shown in Fig. 6. Boxes indicate coding sequences. The heavy black bar indicates the region in which cleavages of Xhox 45 occur; 45 is the RNA from the Xhox 45 cDNA used in previous figures. A 347-base internal SpeI deletion of 45 , including the cleavage region, was used to produce $45 \Delta S p e I$. GM-CSF is RNA from a clone of granulocyte macrophage colony-stimulating factor. 36xl has 200 bases replaced by the 126-base PCR fragment, containing 90 bases of Xhox 45 sequence, as described in Materials and methods. $36 \times 2$ has two 126 -base insertions separated by the inverted 200-base fragment of Xhox36. The construct half-lives were determined by densitometric scanning of lighter exposures of the autoradiographs shown in Fig. 6. The bar below the constructs is 100 bases in length.

the results of Kruys et al. (1989), and is not susceptible to Xhox45-like cleavage.

To determine whether the region to which the cleavage sites map is also sufficient to confer cleavage on another RNA, a 126-base fragment containing 90 bases from Xhox 45 (Fig. 4, underlined) was inserted into Xhox36, as described in Materials and methods. This yielded two plasmids: $36 \times 1$, containing one insert, and $36 \times 2$, containing two inserts separated by a small region of inverted Xhox36 sequence (Fig. 5).

When the modified Xhox36 RNAs from these new constructs were injected and reisolated, they were cut in a manner indistinguishable from that of Xhox45 (Fig. $6 \mathrm{~B}) .36 \mathrm{xl}$, with one copy of the cleavage region insert, has a half-life of $3 \mathrm{hr}$, equal to that of Xhox 45 , and significantly less than the 4.9-hr half-life of Xhox36. 36x2, with two inserts, has a half-life of only $1.7 \mathrm{hr}$. The observed cleavage patterns and half-lives of the constructs shown in Figures 5 and 6 confirm that the sequence in Figure 4a (underlined) is both necessary and sufficient for the endonucleolytic cleavage of mRNA.

\section{Xhox45 cleavage is completely independent of translation and the nuclease activity is stable in the absence of translation}

We tested the effects of both message-specific and global-translation inhibition on Xhox45 RNA degradation, because all previously characterized mRNA degradation systems appear to involve translation of either total cellular RNA or the individual RNA being degraded. Message-specific translation inhibition was accomplished by injecting uncapped RNA, whereas total translation was blocked by incubating oocytes in cycloheximide.

The translation of uncapped, nonviral RNA in oocytes is very inefficient, being reduced by at least $90 \%$ relative to capped RNA (for exceptions, see Lockard and Lane 1978; Banerjee 1980; Drummond et al. 1985). In addition, the stability of uncapped RNA in oocytes has been found to be variable, with half-lives ranging from minutes (Green et al. 1983; Harland and Weintraub 1985) to several hours (Drummond et al. 1985). A large part of these differences appear to be due to the immediate 5 ' sequence of the RNA (B.D. Brown, unpubl.). Fortunately, we find that uncapped, full-length Xhox 45 RNA is almost as stable as capped Xhox 45 , unlike the $3^{\prime}$ fragment resulting from endonucleolytic cleavage. As

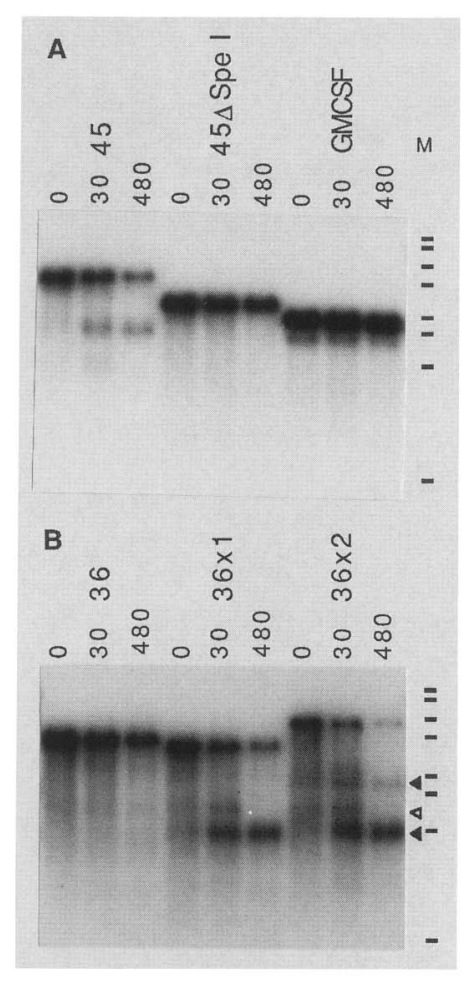

Figure 6. Determination of a region of Xhox 45 that is necessary and sufficient for cleavage. Autoradiograph of RNAs, which were injected, reisolated, and separated on a denaturing agarose gel. The time of reisolation is shown in minutes above the lanes. The half-lives of these RNAs are shown in Fig. 5 . The markers represent $\lambda$ HindIII-EcoRI fragments from $2 \mathrm{~kb}$ to $0.125 \mathrm{~kb}$. (A) Deletion of the cleavage sequence from Xhox 45 eliminates the formation of a discrete cleavage product, as shown in the $45 \Delta S p e$ I lanes. The half-life of $45 \Delta S p e I$ is more than doubled: $7.5 \mathrm{hr}$ for $45 \Delta S p e \mathrm{I}$ compared with $3.3 \mathrm{hr}$ for Xhox45. GM-CSF mRNA was found to be very stable, and even overloading of the RNA does not reveal any distinct degradation products. The small band running slightly below GM-CSF at $\sim 830$ bases is a premature transcription termination product seen in uninjected GM-CSF RNA. (B) Insertion of 90 bases of the $X$ hox 45 cleavage region into $X$ hox 36 causes it to be cleaved in a manner identical to that of Xhox 45 (see also Fig. 8). The open arrowhead marks a premature transcription termination product that was seen in the uninjected $36 \times 1$ and $36 \times 2$ RNAs used in this experiment. The half-lives of Xhox $36,36 \times 1$, and $36 \times 2$ were $4.9,3.0$, and $1.7 \mathrm{hr}$, respectively. The solid arrowheads mark the bands resulting from cleavage in the Xhox 45 insert that are still visible $480 \mathrm{~min}$ after injection. In the $36 \times 2$ sample cleavage at both of the inserts is detectable. 
shown in Figure 7, the uncapped species (lane 6) is cleaved as efficiently as the capped message (lane 2), demonstrating that the cleavage reaction is not dependent on the presence of ribosomes on the Xhox 45 RNA.

Cycloheximide was used to block total protein synthesis both prior to and after mRNA injections. The conditions used were sufficient to inhibit protein synthesis by $97 \%$ (see Materials and methods). In the extreme treatment, oocytes were preincubated in buffer containing cycloheximide for $4 \mathrm{hr}$, injected, and incubated for $4 \mathrm{hr}$ more in the presence of cycloheximide. Cleavage of Xhox 45 is found to be completely unaffected by the inhibition of total protein synthesis (Fig. 7, lanes 9-11). These results support the results of procedures using uncapped RNA and also indicate that the cleavage activity is not labile.

\section{Antisense RNA coinjection blocks the endonuclease activity}

RNA duplexes between coinjected complementary RNAs form rapidly and are stable in Xenopus oocytes, unlike eggs and embryos (Bass and Weintraub 1987; Rebagliati and Melton 1987). Therefore, antisense RNAs to regions of Xhox 45 (diagramed in Fig. 8a) were coinjected with both the Xhox 45 and $36 \times 1$ RNAs to test the effect

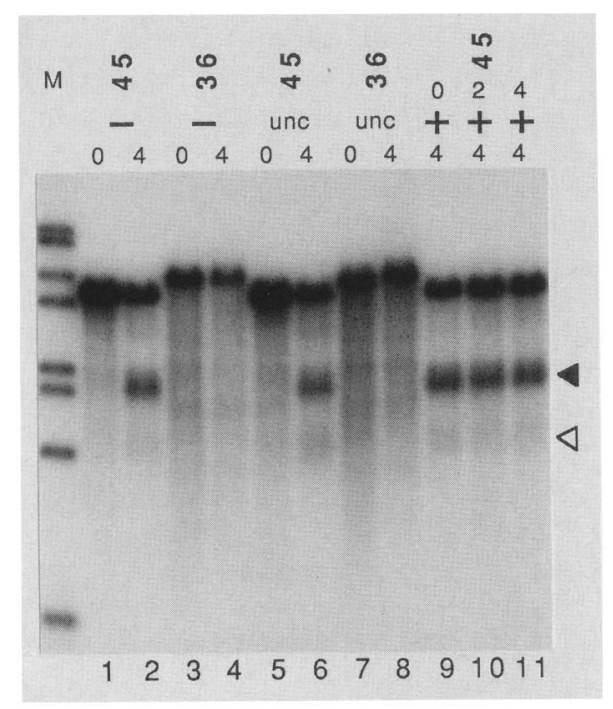

Figure 7. Injection of uncapped RNA or incubation in cycloheximide shows that translation is not required for Xhox 45 cleavage. Xhox 45 and Xhox36 RNAs were injected and analyzed as in Fig. 1. The times at which the RNA samples were reisolated are given in hours above each lane. (Lanes 1 and 2) Capped Xhox45 RNA; (lanes 3 and 4) capped Xhox36 RNA injected into untreated control oocytes $(-)$. Lanes 5-8 are identical to lanes $1-4$, respectively, except the injected RNAs were uncapped (unc) to specifically inhibit translation of the injected RNA. (Lanes 9-11) Xhox45 RNA injected into oocytes that were incubated in cycloheximide to block global translation $(+)$. The lengths of preincubation in cycloheximide is given in hours above the plus marks. The solid arrowhead marks the $5^{\prime}$ fragments that result from cleavage; the open arrowhead marks the faint band caused by the 3 ' RNA fragments. of duplex formation on the endonuclease activity. As seen in Figure $8 b, \alpha d 251$, an antisense RNA that hybridizes to the cleavage region, completely blocked cleavage of Xhox 45 (lane 4), whereas ad191 did not affect the reaction at all (lane 6). $\alpha \mathrm{d} 251$ is also complementary to $36 \mathrm{xl}$, but only in the 90 -base region derived from Xhox 45, and therefore provides a more specific duplexed region. Coinjection with $\alpha \mathrm{d} 251$ with $36 \times 1$ also completely blocked cleavage (lane 10). These results indicate that single-stranded RNA is required for recognition by the endonuclease.

\section{Discussion}

We have presented results showing unequivocally that an endoribonuclease activity cleaves the $3^{\prime}$-untranslated region of the Xhox 45 isolate of the Xenopus homeo boxcontaining gene $X l h b o x 2 B$ in a sequence-specific manner. We have also identified a 90-base sequence from Xhox 45 that is both necessary and sufficient for this endonucleolytic cleavage to occur. A very simple consensus sequence for this region appears to be repeats of a 4-base sequence: ACCT. The functional unit of the cleavage region may be some minimum number of this simple repeat, or it may be as complex as a 19-base repeat that is formed by minor variations in the short repeat: CTACCTACCTACCCACCTA (located around the overlined regions in Fig. 4). To determine the exact recognition site, mutant sequences have been synthesized and inserted into a test transcription template and assayed for biological activity (B.D. Brown, in prep.).

\section{Potential mechanisms of Xhox45 cleavage}

The detection of both the $5^{\prime}$ and $3^{\prime}$ fragments resulting from endonucleolytic cleavage of d21 RNA eliminates a targeted $3^{\prime}$ to $5^{\prime}$ exonuclease as the explanation for the appearance of shortened Xhox45 RNA fragments. Another possibility is that the sequence contains all of the information necessary for self-cleavage. In some cases, self-cleavage activity is inhibited by the formation of alternate secondary structures in RNA and is therefore enhanced in smaller fragments from larger RNAs /Wu et al. 1989). We have never observed self-cleavage of Xhox 45 RNA in vitro under conditions where other self-cleaving RNAs react efficiently (for review, see Cech 1987), even when small RNA fragments containing the entire destabilizing region are incubated in vitro.

Sequence analysis suggests that the destabilizing region does not form any stable Watson-Crick, basepaired secondary structure either internally or with any other region of Xhox 45. Therefore, cleavage of the RNA appears to be based on recognition of a single-stranded molecule, a hypothesis that is also supported by results showing that a small region of Xhox 45 supports cleavage when transferred to another molecule and by results showing that hybridization of an antisense RNA to the cleavage region completely blocks cleavage. This is in strong contrast to histone and transferrin receptor mRNAs, where base-paired RNA structures have been 


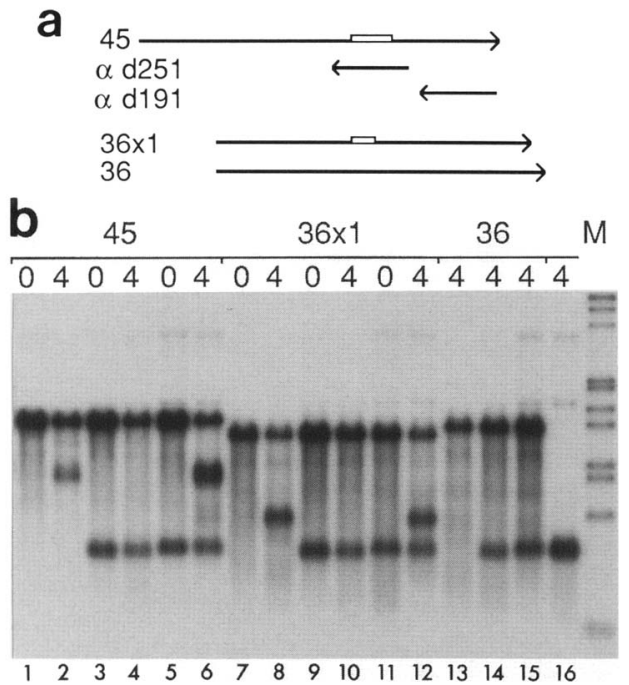

Figure 8. Coinjection of antisense RNA can block the endonuclease activity. (a) Diagram of the constructs injected and shown in $b$. The antisense transcription product of the BS-d251 clone $(\alpha \mathrm{d} 251)$ is complementary to 321 bases of Xhox 45 , and completely covers the endonuclease cleavage region (large open box). $\alpha$ d 191 hybridizes to 283 bases at the extreme $3^{\prime}$ end of $X$ hox 45 , but is almost identical in total length to ad251. The antisense transcripts hybridize to Xhox45 RNA in the positions shown. $\alpha \mathrm{d} 251$ hybridizes to $36 \mathrm{xl}$ only at the 90 -base insert (small open box), and $\alpha \mathrm{d} 191$ does not hybridize to $36 \mathrm{x} 1$ at all. (b) Autoradiograph of RNA injections plus or minus small antisense RNAs. The numbers immediately above each lane indicate hours after injection. The smallest species visible in lanes $3-6,9-12$, and 14 and 15 are due to antisense RNAs (as marked). Normal cleavage of Xhox 45 RNA injected without antisense RNA (lane 2). Coinjection of Xhox 45 with a 10-fold molar excess of ad251 completely blocks the endonuclease (lane 4), while coinjection with $\alpha \mathrm{d} 191$ has no effect on the cleavage reaction (lane 6 ). Injections using the cleavable $36 \times 1$ hybrid RNA (see also Figs. 5 and 6) give the same pattern of results as with $X$ hox $45: 36 \times 1$ alone is cleaved efficiently (lane 8), $\alpha \mathrm{d} 251$ blocks cleavage (lane 10), and $\alpha \mathrm{d} 191$ has no effect (lane 12). (Lane 13) Xhox36 RNA injected alone; (lanes 14 and 15) unmodified Xhox 36 coinjected with $\alpha \mathrm{d} 251$ and $\alpha \mathrm{d} 191$, respectively; (lane 16) $\alpha \mathrm{d} 251$ and $\alpha 191$ injected together. The time after injection is given in hours above each lane. (M) $\lambda$ HindIII/EcoRI markers.

proposed to play critical roles in regulating the stability of these messages (Graves et al. 1987; Casey et al. 1988; Müllner and Kühn 1988). Xhox45 recognition may resemble more closely that of mRNAs such as those encoding growth factors, whose stability is controlled by AU-rich sequences without well-defined secondary structures (Shaw and Kamen 1986; Kabnick and Housman 1988), even though the AUUUA motif is not recognized in oocytes.

The result that Xhox 45 mRNA degradation lacks any requirement for translation is unusual and suggests that this putative endoribonuclease is not associated with either polysomes or individual ribosomes. The presence of the endoribonuclease activity after sustained incubations in cycloheximide also implies that the molecules responsible for this activity are not labile, unlike the c-myc mRNA destabilizing factor reported by Brewer and Ross (1989). These results should greatly simplify the detailed analysis of the cleavage reaction and the biochemical fractionation and characterization of the activity.

\section{Sequence dependence of Xhox45 mRNA cleavage}

Beutler et al. $\{1989)$ have speculated that the UA dinucleotide content of the AU-rich sequence identified by Shaw and Kamen (1986) causes instability due to the presence of a UA-specific ribonuclease. We find that this mechanism cannot account for the cleavage of the Xhox 45 cDNA transcript in Xenopus oocytes. The total UA dinucleotide content of the cleavage region of Xhox 45 is even less than that of the destabilizing region of GM-CSF (19\% vs. $28 \%$, respectively), and we have confirmed the result of Kruys et al. (1989) that GM-CSF mRNA is extraordinarily stable in oocytes. Therefore, based on the UA content alone, Xhox 45 should be more stable than GM-CSF, but we find quite the opposite result. Xenopus oocytes therefore lack an active UA-specific nuclease but do contain an endoribonuclease of a higher sequence specificity.

The cleavage of Xhox 45 in Xenopus oocytes differs from GM-CSF degradation in human cell lines in two significant ways: (1) Xhox 45 cleavage does not require any translation, unlike GM-CSF degradation; and (2) endonucleolytic cleavage of Xhox 45 is the first detectable step, as opposed to the initial poly(A)-shortening event seen with mRNAs that contain the AU-rich sequence (Brewer and Ross 1988; Wilson and Treisman 1988). However, the resemblance between the Xhox45 and GM-CSF instability sequences, as APyPyUA, raises the question of whether the structural recognition of these sequences may be somewhat similar.

Bandyopadhyay et al. (1990) report the detection in vitro of what may be dinucleotide-specific endonucleases on mRNAs from mammalian cells, but the sequences that are apparently required for recognition and cleavage are as yet undefined. The evidence presented suggests that the recognition sequence of the endoribonuclease that attacks Xhox 45 is higher than a dinucleotide. Recognition almost certainly requires more than a tetramer: All of the variations of the tetramer repeat found in the $X$ hox 45 endonuclease recognition region appear randomly in single copies in the other RNAs analyzed in this work, and no corresponding cleavage products were detected (see below).

Stoeckle and Hanafusa (1989) have reported endonucleolytic cleavage of 9E3 mRNA in vivo. Unlike Xhox 45, 9E3 RNA is stabilized by cycloheximide treatment, and the authors speculate that degradation may be due to a self-cleavage reaction that is modulated by labile factors.

\section{Comparison of XlHbox2A and Xlhbox2B cleavage}

Two copies of the XIhbox2 gene are present in the $X e n o p u s$ genome, designated Xlhbox $2 A$ and $X l h b o x 2 B$ (Fritz et al. 1989). The Xhox 45 cDNA is a representative of Xlhbox $2 B$. It is interesting to note that the 123-base 
deletion in the 3' UTR of Xlhbox2A, described by Fritz et al. (1989), removes the cleavage region that we have defined in the Xhox45 isolate $(90$ bases) but that XIhbox2A retains the 15-base sequence CTACCTACCCCACCT around the deletion site. We have tested both Xlhbox2 type A and type B RNA (clones obtained from $C$. Wright and E. DeRobertis) in oocytes and find that only Xlhbox2B RNA is cleaved and that the reaction is indistinguishable from the cleavage of RNA transcribed from the Xhox 45 cDNA (data not shown). The 15-base sequence remaining in Xlhbox2A, though similar to the cleavage region, is insufficient for recognition.

The existence of such a deletion in XIhbox2A, resulting in a gene capable of producing cleavage-resistant transcripts, poses the question of whether or not the transcription of these two genes is differentially regulated at a spatial and/or temporal level. Xlhbox2A could be transcribed whenever the Xlhbox2 protein is needed continuously, whereas the Xlhbox2B mRNA could be transcribed when rapid regulation of the level of protein is needed. The promoter function of these two genes is therefore of particular interest, because Xlhbox2 RNA levels are known to be regulated during oogenesis (Wright et al. 1987).

Because nonadenylated RNAs are measurably less stable in oocytes than polyadenylated RNAs (Drummond et al. 1985), loss of the poly(A) tail and almost all of the 3 '-untranslated region may lead to more rapid turnover of the Xlhbox2B transcript, thus accounting for the changes in Xlhbox2 mRNA levels during oogenesis. Cleavage at this site would almost certainly eliminate $X l h b o x 2 B$ mRNA from the translatable maternal mRNA pool, regardless of the decay rate of the body of the RNA, because poly(A) tails have been shown to be crucial for long-term maintenance of polysomes in oocytes (Galili et al. 1988). Cleavage would also eliminate the possibility of readenylation of XIhbox2B upon maturation of the oocyte, because both the polyadenylation signal itself and any potential hyperadenylation sequence nearby (McGrew et al. 1989) are completely removed.

How general is this potential mechanism of gene expression control? We have screened oocyte-specific and neurula-specific cDNA libraries for other genes containing this cleavage sequence and have found another clone from oocytes with an RNA half-life $<1 \mathrm{hr}$ (B.D. Brown, in prep.), in contrast to the already short half-life of Xlhbox2B. Comparison between this new clone and the Xlhbox2B instability sequences may allow a consensus sequence to be found and a determination of how this motif is used to generate mRNAs with different half-lives.

RNA stability can make a critical contribution to the level of expression of genes (for a theoretical discussion, see Hargrove and Schmidt 1989). Although a considerable amount is known about the general determinants of mRNA stability, far less is known about the enzymes and mechanisms involved in preferentially destabilizing specific mRNAs. In the cases where the instability of individual RNAs has been studied in detail, internal sequences are responsible for the observed rates of turnover, and multiple, independent destabilizing sequences have been found in different regions of mRNAs (Kabnick and Housman 1988; Shyu et al. 1989|. The identification of the sequence-specific cleavage of Xlhbox2B RNA by an endonuclease may lead to a greater understanding of the mechanisms by which the decay of cellular mRNAs in eukaryotes is initiated and regulated.

\section{Materials and methods}

\section{Construction of transcription templates}

The Xhox 45 cDNA clone used in this work was 1342 bases in length, including a 15 -base $5^{\prime}$-untranslated region, a coding region of 660 bases, and a $3^{\prime}$ UTR of 650 bases plus 17 bases of polylinker sequence. The BS-d21 clone consists of the $3^{\prime}$-most 703 bases of the Xhox 45 cDNA clone inserted between the BamHI and EcoRI sites of Bluescript KS- (Stratagene), and when linearized with EcoRI, produces an RNA 752 bases long including polylinker sequence. d21PvuII is RNA produced by linearizing this construct with PvuII, resulting in a 270 -base extension of the $3^{\prime}$ end. Exonuclease III was used to remove the 489 and $3813^{\prime}$-most bases of $\mathrm{BS}^{-} \mathrm{d} 21$ to produce $\mathrm{BS}^{-} \mathrm{d} 272$ and BS $^{-} \mathrm{d} 251$, respectively. A 420-base exonuclease III deletion of BS $^{-}$d21 from the $5^{\prime}$ end was used to produce BS ${ }^{-}$d191.The Xhox36 clone used, 36/12, has been described previously (Condie and Harland 1987) and produces an RNA 1460 bases long, including a coding region of 626 bases and a 3' UTR of 550 bases. $36 \times 1$ and $36 \times 2$ were constructed as follows: A polymerase chain reaction (PCR; Saiki et al. 1988; Taq DNA polymerase from Cetus) was then used to amplify a 126-base fragment containing 90 bases of Xhox 45 sequence out of $\mathrm{BS}^{-} \mathrm{d} 272$. The first primer, 5'-GCTCTAGAGGGTTAGCTACCTACCTACC- $3^{\prime}$, contains the $\mathrm{XbaI}$ restriction site and hybridizes to BS $^{-} \mathrm{d} 272$ at the $5^{\prime}$ end of the cleavage region. The second oligonucleotide, containing the Pst site, is 5'-CGCTGCAGTAAAGGGAACAAAAGCTGGG- $3^{\prime}$ and hybridizes to the Bluescript vector just $3^{\prime}$ of the end of the 272 fragment. The PCR fragment was then cloned into an $X b a \mathrm{I} / \mathrm{P}_{\text {stI-cut } 36 / 125^{\prime}}$ deletion clone named $36.12 \Delta 5^{\prime} 09$. This produced the single-insert clone called $36 \times 1$ and the double-insert clone called $36 \times 2$. The two inserts in $36 \times 2$ are separated by the inverted 206-base $X b a I-P s t I$ fragment of $36.12 \Delta 5^{\prime} 09$. For consistency, the $X$ hox 36 RNA shown in Fig. 5 was transcribed from $36.12 \Delta 5^{\prime} 09$ and is therefore 218 bases shorter than the Xhox36 RNAs shown in Figs. 1 and 2.

\section{In vitro transcriptions and oocyte injections}

Transcriptions were carried out with linearized templates, according to Green et al. (1983), with GpppG (Pharmacia) included in the transcription reaction at a concentration five times greater than the GTP concentration. From 40 to $50 \mu \mathrm{Ci}$ of $\left[\alpha^{-32} \mathrm{P}\right] \mathrm{CTP}$ was also included in each transcription. All reactions were carried out at $37^{\circ} \mathrm{C}$ for $2 \mathrm{hr}$, regardless of the RNA polymerase used. The reactions were then diluted with $0.1 \mathrm{M}$ sodium chloride, $1: 1$ phenol/chloroform-extracted, and precipitated with 0.25 volumes of $10 \mathrm{M}$ ammonium acetate/0.6 volume of isopropanol at room temperature for $30 \mathrm{~min}$. The RNAs were then resuspended in $50 \mu \mathrm{l}$ DEP (diethylpyrocarbonate)-treated water and reprecipitated with 0.5 volume of 10 $\mathrm{M}$ lithium chloride at $-20^{\circ} \mathrm{C}$ for $1 \mathrm{hr}$, followed by an $80 \%$ ethanol wash; they were finally resuspended at $1 \mathrm{mg} / \mathrm{ml}$ in DEPtreated water for injection. Antisense RNAs from BS-d251 and 
d191 were labeled to one-tenth of the specific activity of sense transcripts. Mixtures of 1:10 molar sense/antisense RNA were injected directly without any prehybridization step. Ovaries were obtained from frogs that were from 1.5 to 2 years old. Oocytes were prepared by treating the ovaries with collagenase 12 $\mathrm{mg} / \mathrm{ml}$ ) in modified Barth's saline until the oocytes were released. Stage IV and V oocytes were microinjected with up to 10 $\mathrm{ng}$ ( $20 \mathrm{ng}$ for antisense experiments) of RNA and then incubated at from $20^{\circ} \mathrm{C}$ to $22^{\circ} \mathrm{C}$. Protein synthesis in oocytes was inhibited by incubating oocytes in modified Barth's saline containing $25-30 \mu \mathrm{g} / \mathrm{ml}$ of cycloheximide. As determined by [ ${ }^{35} \mathrm{~S} \mid$ methionine incorporation into TCA-precipitable material, this concentration was sufficient to inhibit protein synthesis by $97 \%$.

\section{RNA analysis}

Five oocytes per sample were homogenized in $500 \mu \mathrm{l}$ of lysis buffer ( $100 \mathrm{~mm} \mathrm{NaCl}, 20 \mathrm{~mm}$ EDTA, $20 \mathrm{~mm}$ Tris, and $1 \% \mathrm{SDS}$ ) containing $200 \mu \mathrm{g} / \mathrm{ml}$ proteinase $\mathrm{K}$ and incubated at $37^{\circ} \mathrm{C}$ for 30 $\min$. They were then frozen and stored at $-20^{\circ} \mathrm{C}$ or processed immediately. After the addition of one-tenth volume of $3 \mathrm{M}$ sodium acetate, the homogenates were extracted with phenol and $1: 1 \mathrm{phenol} / \mathrm{chloroform}$, and then precipitated with 2 volumes of ethanol. These total RNA samples were resuspended in $50 \mu \mathrm{l}$ of DEP-treated water and reprecipitated with 0.5 volume of 10 $M$ lithium chloride at $-20^{\circ} \mathrm{C}$ for $1 \mathrm{hr}$. The samples were then resuspended in $50 \mu \mathrm{l}$ of the appropriate gel sample buffer and run on denaturing $1.4 \%$ agarose/formaldehyde gels, or denaturing $4 \%$ acrylamide $/ 8 \mathrm{~m}$ urea gels, which were then dried. Autoradiography was at room temperature.

\section{Northern blot RNA analysis}

RNA injected for Northern analysis was initially trace-labeled with ${ }^{32} \mathrm{P}$ but was then stored for 14 half-lives so that the label was no longer detectable. Reisolated total RNA, at one oocyte per lane, was run out on a $2.2 \%$ agarose/formaldehyde gel and blotted onto a nylon membrane (Hybond-N, Amersham). The blot was UV-irradiated (Stratalinker, Stratagene), vacuum baked for $2 \mathrm{hr}$, prehybridized for $24 \mathrm{hr}$, and probed with the $3^{\prime}$-specific probe and exposed to film. After stripping and reexposure to confirm the removal of the $3^{\prime}$ probe, the blot was prehybridized again and probed with the $5^{\prime}$-specific probe. Probes labeled with ${ }^{32} \mathrm{P}$ were made by random oligo-primed synthesis by use of the appropriate gel-purified DNA fragments as described in the text.

\section{Oligonucleotide/RNase H RNA analysis}

The same d21 RNA isolated 80 min after injection shown in the Northern blot in Figure 2 and described above was used for DNA oligonucleotide-mediated RNase $\mathrm{H}$ cleavage of specific RNA fragments. The 5 '-specific oligomer 5'-TAGTCCATTGGGGCCACTTCATTC-3' hybridizes to d21 RNA from bases 681 to 658 (Fig. 4), and the $3^{\prime}$-specific oligomer $5^{\prime}$-ACATAGAAAGTGGTTGTACAGAGG-3' hybridizes from bases 888 to 865 . Total injected oocyte RNA samples from one oocyte each (minus oligomers, plus $5^{\prime}$ oligomer, and plus $3^{\prime}$ oligomer) were denatured at $90^{\circ} \mathrm{C}$ for $5 \mathrm{~min}$ and incubated for $2 \mathrm{hr}$ at $42^{\circ} \mathrm{C}$ in $300 \mathrm{~mm} \mathrm{NaCl}, 10 \mathrm{~mm}$ Tris, $1 \mathrm{~mm}$ EDTA (final $\mathrm{pH}$ of 7.5), and precipitated. Each sample was then resuspended in $50 \mu \mathrm{l}$ of 100 $\mathrm{mM} \mathrm{KCl}, 10 \mathrm{~mm} \mathrm{MgCl} 2,20 \mathrm{~mm}$ Tris, $0.1 \mathrm{~mm}$ dithiothreitol, 5\% sucrose (final $\mathrm{pH}$ of 7.5), and 0.5 units RNase $\mathrm{H}$ (Bethesda Research Laboratories) and incubated at $37^{\circ} \mathrm{C}$ for $30 \mathrm{~min}$. Glycogen was then added as a carrier, and the samples were precipitated, resuspended in sample buffer, run out on a $2.2 \%$ agarose/ formaldehyde gel, blotted onto nylon, and probed as described above, except that the probe was synthesized from full-length d21 DNA fragments.

\section{S1 nuclease protection}

The DNA probe to detect $5^{\prime}$ fragments was labeled by filling the BamHI site of $\mathrm{BS}^{-} \mathrm{d} 272$ with $3000 \mathrm{Ci} / \mathrm{mmole}^{\left.-\alpha^{-32} \mathrm{P}\right] \mathrm{dCTP}}$ (Amersham) and reverse transcriptase (Life Sciences), and cutting with KpnI in the Bluescript polylinker. The $5^{\prime}$-sequencing ladder was generated using Maxam-Gilbert sequencing reactions on the $5^{\prime}$ probe. The $3^{\prime}$ fragment probe was made by phosphorylating an oligonucleotide complementary to bases $865-888$ of the d21 sequence with $>5000 \mathrm{Ci} / \mathrm{mmole}$ $\left[\gamma^{-32} \mathrm{P}\right] \mathrm{ATP}$ and polynucleotide kinase, extending it with the Klenow fragment, and cutting with BamHI. The $3^{\prime}$ sequence ladder was generated by using the same labeled oligonucleotide in T7 DNA polymerase/dideoxynucleotide sequencing reactions (Pharmacia). The 5'- and 3 '-specific probes were purified on strand-separating and denaturing acrylamide gels, respectively. For the Sl nuclease protection reactions, the total RNA reisolated from one-fifth to one-tenth of an oocyte was mixed with an approximately 10 -fold molar excess of probe and $40 \mu \mathrm{g}$ of torula RNA and hybridized at $65^{\circ} \mathrm{C}$ for $3 \mathrm{hr}$. The reactions contained from 60 to 90 units of S1 nuclease and were incubated at $37^{\circ} \mathrm{C}$ for up to $45 \mathrm{~min}$.

\section{Acknowledgments}

We thank Elizabeth Blackburn, Mike Botchan, and the members of our group for a critical reading of the manuscript. B.D.B. thanks Merrill B. Hille for excellent training. The GMCSF clone was obtained from M. Kriegler (Cetus, Emeryville, CA), and the Xlhbox2A and Xlhbox2B clones were obtained from C.V.E. Wright and E. DeRobertis. This work was supported by the National Institutes of Health.

The publication costs of this article were defrayed in part by payment of page charges. This article must therefore be hereby marked "advertisement" in accordance with 18 USC section 1734 solely to indicate this fact.

\section{References}

Bandyopadhyay, R., M. Coutts, A. Krowczynska, and G. Brawerman. 1990. Nuclease activity associated with mammalian mRNA in its native state: Possible basis for selectivity in mRNA decay. Mol. Cell. Biol. 10: 2060-2069.

Banerjee, A.K. 1980. 5'-Terminal cap structure in eukaryotic messenger ribonucleic acids. Microbiol. Rev. 44: 175-205.

Bass, B.L. and H. Weintraub. 1987. A developmentally regulated activity that unwinds RNA duplexes. Cell 48: 607-613.

Bergmann, I.E. and G. Brawerman. 1977. Control of breakdown of the polyadenylate sequence in mammalian polyribosomes: Role of poly(adenylic acid)-protein interactions. Biochemistry 16: 259-264.

Bernstein, P., S.W. Peltz, and J. Ross. 1989. The poly(A)poly(A)-binding protein complex is a major determinant of mRNA stability in vitro. Mol. Cell. Biol. 9: 659-670.

Beutler, E., T. Gelbart, J. Han, J.A. Koziol, and B. Beutler. 1989. Evolution of the genome and the genetic code: Selection at the dinucleotide level by methylation and polyribonucleotide cleavage. Proc. NatI. Acad. Sci. 86: 192-196.

Brawerman, G. 1987. Determinants of messenger RNA stability. Cell 48: 5-6.

. 1989. mRNA decay: Finding the right targets. Cell 57: 9-10.

Brewer, G. and J. Ross. 1988. Poly(A) shortening and degradation of the $3^{\prime} \mathrm{A}+\mathrm{U}$-rich sequences of human c-myc mRNA in a cell-free system. Mol. Cell. Biol. 8: 1697-1708. 
- 1989. Regulation of $c-m y c$ mRNA stability in vitro by a labile destabilizer with an essential nucleic acid component. Mol. Cell. Biol. 9: 1996-2006.

Casey, J.L., M.W. Hentze, D.M. Koeller, S.W. Caughman, R.A. Rouault, R.D. Klausner, and J.B. Harford. 1988. Iron-responsive elements: Regulatory RNA sequences that control mRNA levels and translation. Science 240: 924-928.

Cech, T.R. 1987. The chemistry of self-splicing RNA and RNA enzymes. Science 236: 1532-1539.

Cleveland, D.W. and T.J. Yen. 1989. Multiple determinants of eukaryotic mRNA stability. New Biologist 1: 121-126.

Colot, H.V. and M. Rosbash. 1982. Behavior of individual maternal pA + RNAs during embryogenesis of Xenopus laevis. Dev. Biol. 94: 79-86.

Condie, B.G. and R.M. Harland. 1987. Posterior expression of a homeo box gene in early Xenopus embryos. Development 101: 93-105.

Drummond, D.R., J. Armstrong, and A. Colman. 1985. The effect of capping and polyadenylation on the stability, movement, and translation of synthetic messenger RNAs in Xenopus oocytes. Nucleic Acids Res. 13: 7375-7394.

Dworkin, M.B. and E. Dworkin-Rastl. 1985. Changes in RNA titers and polyadenylation during oogenesis and oocyte maturation in Xenopus laevis. Dev. Biol. 112: 451-457.

Dworkin, M.B., Shrutkowski, A., and E. Dworkin-Rastl. 1985. Mobilization of specific maternal RNA species into polysomes after fertilization in Xenopus laevis. Proc. Natl. Acad. Sci. 82: 7636-7640.

Ford, P.J., T. Mathieson, and M. Rosbash. 1977. Very long-lived messenger RNA in ovaries of Xenopus laevis. Dev. Biol. 57: 417-426.

Fritz, A.F., K.W.Y. Cho, C.V.E. Wright, B.G. Jegalian, and E.M. DeRobertis. 1989. Duplicated homeo box-containing genes in Xenopus. Dev. Biol. 131: 584-588.

Furuichi, Y., A. LaFiandra, and A.J. Shatkin. 1977. 5'-terminal structure and mRNA stability. Nature 266: 235-239.

Galili, G., E.E. Kawata, L.D. Smith, and B.A. Larkins. 1988. Role of the $3^{\prime}$-poly(A) sequence in translational regulation of mRNAs in Xenopus laevis oocytes. $I$. Biol. Chem. 263: 5764-5770.

Golden, L., U. Schafer, and M. Rosbash. 1980. Accumulation of individual pA + RNAs during oogenesis of Xenopus laevis. Cell 22: 835-844.

Graves, R.A., N.B. Pandey, N. Chodchoy, and W.F. Marzluff. 1987. Translation is required for regulation of histone mRNA degradation. Cell 48: 615-626.

Green, M.R., T. Maniatis, and D.A. Melton. 1983. Human $\beta$ globin pre-mRNA synthesized in vitro is accurately spliced in Xenopus oocyte nuclei. Cell 32: 681-694.

Hargrove, J.L. and F.H. Schmidt. 1989. The role of mRNA and protein stability in gene expression. FASEB I. 3: 2360-2370.

Harland, R.M. and H. Weintraub. 1985. Translation of mRNA injected into Xenopus oocytes is specifically inhibited by antisense RNA. J. Cell Biol. 101: 1094-1099.

Harland, R.M. and L. Misher. 1988. Stability of RNA in developing Xenopus embryos and identification of a destabilizing sequence in TFIIIA messenger RNA. Development 102: $837-852$.

Hyman, L.E. and W.M. Wormington. 1988. Translational inactivation of ribosomal protein mRNAs during Xenopus oocyte maturation. Genes Dev. 2: 598-605.

Jackson, R.J. and N. Standart. 1990. Do the poly(A) tail and 3' untranslated region control mRNA translation? Cell 62: $15-24$.

Kabnick, K.S. and D.E. Housman. 1988. Determinants that contribute to cytoplasmic stability of human c-fos and $\beta$-globin
mRNAs are located at several sites in each mRNA. Mol. Cell. Biol. 8: 3244-3250.

Kruys, V., O. Marinx, G. Shaw, J. Deschamps, and G. Huez. 1989. Translation blockade imposed by cytokine-derived UA-rich sequences. Science 245: 852-855.

Lockard, R.E. and C. Lane. 1978. Requirement for 7-methylguanosine in translation of globin mRNA in vivo. Nucleic Acids Res. 5: 3237-3247.

McGrew, L.L., E. Dworkin-Rastl, M.B. Dworkin, and J.D. Richter. 1989. Poly(A) elongation during Xenopus oocyte maturation is required for translational recruitment and is mediated by a short sequence element. Genes Dev. 3: 803815.

Müllner, E.W. and L.C. Kühn. 1988. A stem-loop in the $3^{\prime}$ untranslated region mediates iron-dependent regulation of transferrin receptor mRNA stability in the cytoplasm. Cell 53: $815-825$.

Müller, M.M., A.E. Carrasco, and E.M. DeRobertis. 1984. A homeo-box-containing gene expressed during oogenesis in Xenopus. Cell 39: 157-162.

Pachter, J.S., T.J. Yen, and D.W. Cleveland. 1987. Autoregulation of tubulin expression is achieved through specific degradation of polysomal tubulin mRNAs. Cell 51: 283-292.

Rebagliati, M.R. and D.A. Melton. 1987. Antisense RNA injections in fertilized frog eggs reveal an RNA duplex unwinding activity. Cell 48: 599-605.

Ross, J. 1988. Messenger RNA turnover in eukaryotic cells. Mol. Biol. Med. 5: 1-14.

Sachs, A.B. and R.W. Davis. 1989. The poly(A) binding protein is required for poly(A) shortening and $60 \mathrm{~S}$ ribosomal subunit-dependent translation initiation. Cell 58: 857-867.

Saiki, R.K., D.H. Gelfand, S. Stoffel, S.J. Scharf, R. Higuchi, G.T. Horn, K.B. Mullis, and H.A. Erlich. 1988. Primer-directed enzymatic amplification of DNA with a thermostable DNA polymerase. Science 239: 487-491.

Shapiro, D.J., J.E. Blume, and D.A. Nielsen. 1987. Regulation of messenger RNA stability in eukaryotic cells. Bioessays 6: 221-226.

Shaw, G. and R. Kamen. 1986. A conserved AU sequence from the $3^{\prime}$ untranslated region of GM-CSF mRNA mediates selective mRNA degradation. Cell 46: 659-667.

Shyu, A.-B., M.E. Greenberg, and J.G. Belasco. 1989. The c-fos transcript is targeted for rapid decay by two distinct mRNA degradation pathways. Genes Dev. 3: 60-72.

Stoeckle, M.Y. and H. Hanafusa. 1989. Processing of 9E3 mRNA and regulation of its stability in normal and Rous sarcoma virus-transformed cells. Mol. Cell. Biol. 9: 4738-4745.

Wilson, T. and R. Treisman. 1988. Removal of poly(A) and consequent degradation of c-fos mRNA facilitated by $3^{\prime}$ AUrich sequences. Nature 336: 396-399.

Wright, C.V.E., K.W.Y. Cho, A. Fritz, T.R. Bürglin, and E.M. DeRobertis. 1987. A Xenopus laevis gene encodes both homeo box-containing and homeo box-less transcripts. $E M B O$ I. 6: 4083-4090.

Wu, H.-N., Y.-J. Lin, F.-P. Lin, S. Makino, M.-F. Chang, and M.M.C. Lai. 1989. Human hepatitis $\delta$ virus RNA subfragments contain an autocleavage activity. Proc. Natl. Acad. Sci. 86: $1831-1835$.

Xing Y.Y. and A. Worcel. 1989. A 3' exonuclease activity degrades the pseudogene 5S RNA transcript and processes the major oocyte 5S RNA transcript in Xenopus oocytes. Genes Dev. 3: 1008-1018.

Yen, T.J., P.S. Machlin, and D.W. Cleveland. 1988. Autoregulated instability of $\beta$-tubulin mRNAs by recognition of the nascent amino terminus of $\beta$-tubulin. Nature 334: 580-585. 


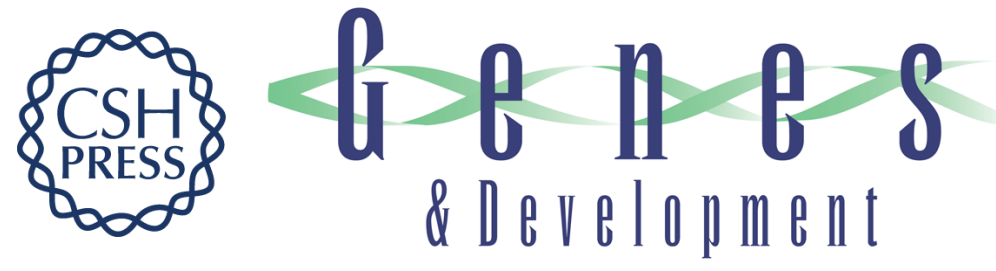

\section{Endonucleolytic cleavage of a maternal homeo box mRNA in Xenopus oocytes.}

B D Brown and R M Harland

Genes Dev. 1990, 4:

Access the most recent version at doi:10.1101/gad.4.11.1925

References This article cites 50 articles, 22 of which can be accessed free at:

http://genesdev.cshlp.org/content/4/11/1925.full.html\#ref-list-1

License

Email Alerting

Service

Receive free email alerts when new articles cite this article - sign up in the box at the top right corner of the article or click here.

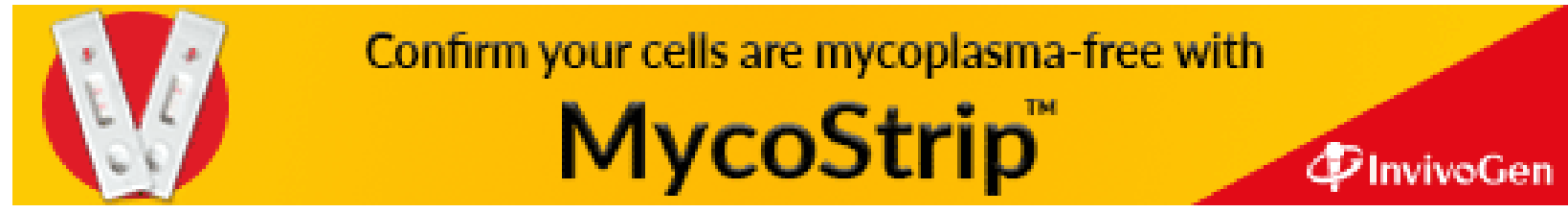

